\title{
Effect of CO Concentration on the $\alpha$-Value of Plasma-Synthesized Co/C Catalyst in Fischer-Tropsch Synthesis
}

\author{
James Aluha ${ }^{1}$, Yongfeng $\mathrm{Hu}^{2}$ and Nicolas Abatzoglou ${ }^{1, *}$ \\ 1 Department of Chemical \& Biotechnological Engineering, Université de Sherbrooke, Sherbrooke, \\ QC J1K 2R1, Canada; james.aluha@usherbrooke.ca \\ 2 Canadian Light Source Inc., Saskatoon, SK S7N 2 V3, Canada; yongfeng.hu@lightsource.ca \\ * Correspondence: nicolas.abatzoglou@usherbrooke.ca; Tel.: +1-819-821-7904 \\ Academic Editor: Leonarda F. Liotta
}

Received: 28 December 2016; Accepted: 13 February 2017; Published: 21 February 2017

\begin{abstract}
A plasma-synthesized cobalt catalyst supported on carbon $(\mathrm{Co} / \mathrm{C})$ was tested for Fischer-Tropsch synthesis (FTS) in a 3-phase continuously-stirred tank slurry reactor (3- $\phi$-CSTSR) operated isothermally at $220{ }^{\circ} \mathrm{C}(493 \mathrm{~K})$, and $2 \mathrm{MPa}$ pressure. Initial syngas feed stream of $\mathrm{H}_{2}: \mathrm{CO}$ ratio $=2$ with molar composition of $0.6 \mathrm{~L} / \mathrm{L}(60 \mathrm{vol} \%) \mathrm{H}_{2}$ and $0.3 \mathrm{~L} / \mathrm{L}(30 \mathrm{vol} \%) \mathrm{CO}$, balanced in $0.1 \mathrm{~L} / \mathrm{L}(10 \mathrm{vol} \%)$ Ar was used, flowing at hourly space velocity (GHSV) of $3600 \mathrm{~cm}^{3} \cdot \mathrm{h}^{-1} \cdot \mathrm{g}^{-1}$ of catalyst. Similarly, other syngas feed compositions of $\mathrm{H}_{2}: \mathrm{CO}$ ratio $=1.5$ and 1.0 were used. Results showed $\sim 40 \%$ CO conversion with early catalyst selectivity inclined towards formation of gasoline $\left(\mathrm{C}_{4}-\mathrm{C}_{12}\right)$ and diesel $\left(\mathrm{C}_{13}-\mathrm{C}_{20}\right)$ fractions. With prolonged time-on-stream (TOS), catalyst selectivity escalated towards the heavier molecular-weight fractions such as waxes $\left(C_{21+}\right)$. The catalyst's $\alpha$-value, which signifies the probability of the hydrocarbon-chain growth was empirically determined to be in the range of $0.85-0.87\left(\right.$ at $\mathrm{H}_{2}: \mathrm{CO}$ ratio $\left.=2\right)$, demonstrating prevalence of the hydrocarbon-chain propagation, with particular predisposition for wax production. The inhibiting CO effect towards FTS was noted at molar $\mathrm{H}_{2}$ :CO ratio of 1.0 and 1.5, giving only $\sim 10 \%$ and $\sim 20 \% \mathrm{CO}$ conversion respectively, although with a high $\alpha$-value of 0.93 in both cases, which showed predominant production of the heavier molecular weight fractions.
\end{abstract}

Keywords: alpha-value; cobalt-catalyst; plasma-synthesis; carbon; Fischer-Tropsch

\section{Introduction}

At present, South African Synthetic Oil Ltd., (SASOL) operates the world largest coal liquefaction plants and it produces synthetic fuels commercially through Fischer-Tropsch catalysis. Syngas, a mixture of carbon monoxide and hydrogen $\left(\mathrm{CO}+\mathrm{H}_{2}\right)$ is polymerized to a myriad of hydrocarbon products with $-\mathrm{CH}_{2}$ - being considered as the basic monomer, as illustrated in sample Equation (1) by Thomas and Thomas [1] (p. 526). In addition to fuels and oils, Sasol produces locomotive and industrial lubricants, greases and solid waxes, cleansers and degreasing agents, besides a full spectrum of chemicals that include solvents, ammonia, mining reagents, explosives and polymers such as polyethylene, polypropylene and polyvinyl chloride.

$$
n \mathrm{CO}+2 n \mathrm{H}_{2} \rightarrow-\left[\mathrm{CH}_{2}\right]_{n}-+n \mathrm{H}_{2} \mathrm{O}
$$

In the production of high molecular-weight hydrocarbons such as diesel and waxes, a Co-based catalyst is normally preferred. Although the catalyst exhibits high activity and long life in the low-temperature Fischer-Tropsch synthesis (LT-FTS) regime, exposure to high temperatures results 
in carbon deposition on metal-oxide supports such as $\mathrm{Al}_{2} \mathrm{O}_{3}, \mathrm{SiO}_{2}$ or $\mathrm{TiO}_{2}$, which is detrimental to the catalyst's structural integrity [2]. However, there is a view that a carbon-supported catalyst may not be impacted in a similar way because of its resistance to both carbon fouling and carburization effects [3]. For this reason, we are advocating for the application of plasma-generated graphitic carbon as an effective FTS catalyst support in this study. Indeed some authors have observed the value carburization process can offer in catalyst regeneration. For example, Equation (2) shows a proposed mechanism of regenerating a Co-based FTS catalyst through carburization by initially forming the less active $\mathrm{Co}_{2} \mathrm{C}$ phase, followed by reduction in $\mathrm{H}_{2}$ [4].

$$
\mathrm{CoO} \stackrel{\mathrm{CO}}{\rightarrow} \mathrm{Co}_{2} \mathrm{C} \stackrel{\mathrm{H}_{2}}{\rightarrow} \mathrm{Co}
$$

Moreover, the graphitic carbon-support structure has been noted to enhance catalyst selectivity towards high molecular weight fractions with more than five carbon atoms in the hydrocarbon chain $\left(\mathrm{C}_{5+}\right)$ by facilitating electron transfer between the $\mathrm{Co}$ metal and $\mathrm{CO}$ molecules during FTS [5]. It has been observed that certain desirable properties of the $C$ support can easily be activated, enhanced or varied by functionalization using either basic or acidic media [6]. In fact, the very presence of carbon as a support does not seem to negatively influence the performance of the nanometric carbon-supported catalysts that were synthesized through plasma [7]. In the recent past, great interest has been stimulated in catalyst preparation by various plasma technologies because plasma produces materials that have improved LT-FTS activity, enhanced stability, and have better anti-carbon deposition performance [8]. In LT-FTS, a comparative study of identical single-metal $\mathrm{Co} / \mathrm{C}$ catalysts produced by various methods showed that induction suspension plasma-spray (SPS) technology produces superior FTS catalysts [9].

Another approach that has been applied in FTS to improve selectivity towards the $\mathrm{C}_{5+}$ products is through $\mathrm{CO}$-enriched syngas feeds, which lowers $\mathrm{CH}_{4}$ formation [10]. Nevertheless, where gas composition has been used to determine the product spectrum, low $\mathrm{CO}$ conversions have prevailed, with an increased reaction rate being observed at higher $\mathrm{H}_{2}: \mathrm{CO}$ ratios above 1.6 , and this has an added advantage of using less catalyst quantities for the same feed conversion [2]. Since natural resources such as coal are finite, pursuit for alternative carbon sources and the use of CO-rich syngas of biomass origin is contemplated [11], and may present benefits that comprise sustainability through production of biomass-derived fuels. Interest in a Biomass to Liquid process via Fischer-Tropsch (BTL-FT) synthesis is growing steadily from both academia and industry because of its ability to produce carbon neutral and environmentally friendly clean fuels [12]. Commercial production of such fuels while simultaneously satisfying the increasing energy demand and meeting stringent environmental regulations is inevitable in the foreseeable future, particularly with the push towards sulphur-free diesel [13]. The world today is therefore bracing itself for compliance in automobile fuel production; to shift away from fossil fuels towards renewable sources of energy such as biomass.

A number of theories have been developed to elucidate the polymerization mechanisms that influence FTS product selectivity. In order to determine $\alpha$, the probability of a catalyst being selective towards the formation of $\mathrm{C}_{5+}$ products, the Anderson-Schulz-Flory (ASF) distribution model shown in Equation (3) is normally applied [14]. The $\alpha$-value is calculated from the gradient of the linearized expression in the plot of $\log \left(\mathrm{M}_{n} / n\right)$ versus $\mathrm{n}$, given as Equation (4) [15] (p. 403).

$$
\begin{gathered}
\frac{M_{n}}{n}=(1-\alpha)^{2} \cdot \alpha^{(n-1)} \\
\ln \alpha=n \ln \alpha+\ln \left[\frac{(1-\alpha)^{2}}{\alpha}\right]
\end{gathered}
$$

where:

$M_{n}=$ mole fraction of a hydrocarbon with chain length $n$

$n=$ number of total carbon atoms 
$\alpha=$ probability of chain growth $(\alpha<1)$

$(1-\alpha)=$ probability of chain termination

Although being more expensive than the Fe-based catalyst, the Co catalyst is preferred for the production of long-chain paraffins because of its high activity and low water-gas shift activity [16]. On one hand, strong interaction between the metallic phase and the support has been observed to improve catalytic activity [17], but on the other hand, it may be detrimental due to the formation of irreducible metal-support compounds such as cobalt aluminate or cobalt silicate by way of incorporating $\mathrm{CoO}$ into the $\mathrm{Al}_{2} \mathrm{O}_{3}$ or $\mathrm{SiO}_{2}$ support respectively [18], thereby leading to catalyst deactivation. In addition, carburization of the Co catalyst may lead to deactivation since the cobalt carbide $\left(\mathrm{CO}_{2} \mathrm{C}\right)$ formed is not a catalytically active material for FTS [4], though it has been observed to enhance the activity of the Fe-based catalyst [19]. Other causes of catalyst deactivation include coking, surface restructuring of the Co metal phase in syngas, and sintering of the Co nanoparticles [20]. Some authors have equally suggested that Co-metal re-oxidation may also lead to catalyst deactivation [21], although there are some disagreements based on particle size effects as shown by empirical data [22].

Nevertheless, one method that has been adopted in solving catalyst deactivation issues is by addition of promoters. For example, precious metals like $\mathrm{Au}$ [23], and Pt [24], or in some cases, $\mathrm{Ru}$ have been employed to create multi-component catalysts such as $\left(\mathrm{Ru}+\mathrm{Co}+\mathrm{Mn} / \mathrm{Zr} / \mathrm{SiO}_{2}\right)$ to enhance Co reducibility [25]. This alters catalyst activity and selectivity or the catalyst's preference for a specific reaction mechanism [26], although some elements acting as promoters have been observed to aggravate metal particle sintering of the metal nanoparticles [27]. Other complex catalyst formulations such as carbon-supported cobalt manganese oxide $\left(\mathrm{CoMnO}_{x}\right)$ catalysts [28], are currently being developed.

In this article, we limit our discussion to an approach that does not involve promoters because the single-metal $\mathrm{Co} / \mathrm{C}$ catalyst is under scrutiny. Since one of the major causes of deactivation in Co-based catalysts is carbon deposition [29], in this project, a carbon support was envisaged for a permanent solution. Table 1 indicates a selected number of Co-based catalysts used in FTS reaction that were supported on various materials ranging from metal oxides to elemental carbon that has received considerable attention in the recent past. The Co metal may be added to the support using different approaches such as impregnation or precipitation, but currently the plasma technology is advancing, both in catalyst synthesis and activation. Although most researchers test the catalysts in the fixed-bed reactor with the $\mathrm{H}_{2}: \mathrm{CO}$ ratio of $\sim 2$ at $220{ }^{\circ} \mathrm{C}$ and $2 \mathrm{MPa}$ pressure, in this study the slurry reactor operating under similar reaction conditions has been chosen.

In our earlier work, catalyst activity was determined by real-time analysis of the unreacted $\mathrm{CO}$ in the reactor effluent-gas stream, from which $\mathrm{CO}$ conversion was calculated. However, one of the constraints of our earlier reactor set-up was that similar real-time liquid-phase analysis was not possible, since it required total cooling of the reactor preferably overnight in order to sample the slurry. In doing so, a lot of valuable information from the liquid-phase was inaccessible until after over $36 \mathrm{~h}$ from the commencement of the reaction. This necessitated for a modification of our reactor system, where we have devised a method of analyzing the liquid-phase in order to determine the composition of the heavier hydrocarbons $\left(\mathrm{C}_{5+}\right)$ in real time as the reaction progresses. Having a family of eight plasma-synthesized catalysts based on $\mathrm{Co}$ and $\mathrm{Fe}$ [30], the most active material at the lower temperatures of $160-220^{\circ} \mathrm{C}$ was the single $\mathrm{Co} / \mathrm{C}$ catalyst, which we have selected to use in this study.

Since the previous publication on the single-metal Co/C was centred on catalyst synthesis, characterization and benchmarking with the commercially available Fe-NanoCat ${ }^{\circledR}$ catalyst [7], one of the limitation in determining the true $\alpha$-value of the catalyst was due to the reactor set-up. The plasma-synthesized Co/C was tested in a closed 3- $\phi$-CSTSR for FTS. In the current reactor set up, the true $\alpha$-value of the catalyst may be calculated because there is minimum time required to generate a reasonable amount of polymerization, which if not observed can lead to a wrong determination. 
Table 1. Some Co catalysts that have been tested in typical FTS reaction conditions.

\begin{tabular}{|c|c|c|c|c|c|c|c|c|c|c|}
\hline \multirow[b]{2}{*}{ Catalyst } & \multicolumn{3}{|c|}{ Catalyst } & \multicolumn{6}{|c|}{ FTS Reaction } & \multirow[b]{2}{*}{ Reference } \\
\hline & $\begin{array}{l}\text { Synthesis } \\
\text { Method * }\end{array}$ & Support $\#$ & $\begin{array}{l}\text { Metal Particle } \\
\text { Size }(\mathrm{nm})^{\theta}\end{array}$ & Reactor & $\begin{array}{c}\text { GHSV } \\
\left(\mathrm{cm}^{3} \cdot \mathrm{g}^{-1} \cdot \mathrm{h}^{-1}\right)\end{array}$ & $\mathrm{H}_{2}: \mathrm{CO}$ & $\begin{array}{c}\text { Pressure } \\
\text { (MPa) }\end{array}$ & Temp $\left({ }^{\circ} \mathrm{C}\right)$ & $\begin{array}{c}\% \mathrm{CO} \\
\text { Conversion }\end{array}$ & \\
\hline $\mathrm{Co} / \mathrm{Al}_{2} \mathrm{O}_{3}$ & IWI & $\mathrm{Al}_{2} \mathrm{O}_{3}$ & $11-28$ & Fixed-bed & $6100-9500$ & 2.1 & 2 & 210 & 50 & [31] \\
\hline $\mathrm{Co} / \mathrm{C}$ & IWI & CNTs & $9-24$ & Fixed-bed & 2000 & 2 & 2 & 270 & 90 & [32] \\
\hline $\mathrm{Co} / \mathrm{C}$ & IWI & CNTs & $4-20$ & Fixed-bed & 3600 & 2 & 2 & 220 & 50 & [33] \\
\hline $\mathrm{Co} / \mathrm{C}$ & DBD-plasma & CNTs & $5-26$ & Fixed-bed & 1800 & 2 & 2 & 230 & 95 & [34] \\
\hline $\mathrm{Co} / \mathrm{C}$ & IWI, DP, IA & CNFBs & $2.6-27$ & Plug-flow & - & 2 & 3.5 & $210-250$ & $60-80$ & [35] \\
\hline $\mathrm{Co} / \mathrm{C}$ & Induction SPS & Carbon & $9-11$ & CSTR & 3600 & 2 & 2 & 220 & 42 & [7] \\
\hline $\mathrm{Co} / \mathrm{SiC}$ & $\mathrm{IM}$ & $\mathrm{SiC}$ & $15-35$ & Fixed-bed & 6000 & 2 & 2 & $\begin{array}{l}220 \\
250\end{array}$ & $\begin{array}{l}25 \\
92\end{array}$ & {$[36]$} \\
\hline $\mathrm{Co} / \mathrm{SiO}_{2}$ & - & $\mathrm{SiO}_{2}$ & - & Fixed-bed & 6000 & 1.9 & $1.5-2.5$ & 230 & 42 & {$[37,38]$} \\
\hline $\mathrm{Co} / \mathrm{SiO}_{2}$ & IWI, GD-plasma & $\mathrm{SiO}_{2}$ & $5.8-10.2$ & Fixed-bed & 1800 & 2 & 0.1 & 220 & 22 & [39] \\
\hline $\mathrm{Co} / \mathrm{TiO}_{2}$ & DP, IWI & $\mathrm{TiO}_{2}$ & 2-13 & Fixed-bed & $3450-5850$ & 2 & 2 & 220 & 35 & [40] \\
\hline
\end{tabular}

FTS = Fischer-Tropsch synthesis; GHSV = gas hourly space velocity; CSTR = continuously-stirred tank reactor. * CP = Co-precipitation; DP = Deposition-precipitation; IA = Ion adsorption; $\mathrm{IM}=$ Impregnation method; IWI = Incipient wetness impregnation; DBD = dielectric-barrier discharge plasma (treatment); GD = Glow discharge (treatment); SPS = suspension-plasma spray (synthesis); ${ }^{\theta}$ Mean metal particle size varies in the data depending on analytical technique applied (e.g., Transmission Electron Microscopic (TEM) imaging, X-ray Diffraction (XRD), Chemisorption); ${ }^{\$}$ The highest $\mathrm{CO}$ conversion achieved is reported here; ${ }^{\#} \mathrm{CNT}=$ Carbon nanotubes; $\mathrm{CNFBs}=$ Carbon nanofibres. 
Therefore, the objectives of this work was: (i) to develop a safe sampling method of the slurry from the reactor, which was both hot and at high-pressure, without significantly interrupting the FTS reaction process or being exposed to the highly toxic $\mathrm{CO}$; (ii) to illustrate hydrocarbon-chain propagation with TOS by providing empirical evidence for the gradual development of the longer-chain hydrocarbons using this novel sampling method; (iii) to determine the true $\alpha$-value of the Co/C catalyst, while observing for the least time required for maximum possible polymerization to occur; and (iv) to investigate the effect of using CO-rich syngas feed stream on the LT-FTS product distribution, with a view that the current $\mathrm{H}_{2}$-rich syngas derived from natural gas will eventually be replaced by the CO-rich biomass-derived syngas. In characterizing the materials' properties, we have motivated for the catalysts' potential suitability in FTS application since the materials have been found to be both nanometric and non-porous [30]. Therefore, in this paper, we report for the first time the effect of feed gas composition on the catalyst's $\alpha$-value with TOS as projected from the FTS product distribution using the plasma-synthesized catalyst supported on carbon $(\mathrm{Co} / \mathrm{C})$.

\section{Results}

\subsection{Catalyst Characterization}

The catalyst under review has already been fully characterized by Brunauer-Emmett-Teller (BET) specific surface area analysis and porosity, Raman spectroscopy, Thermogravimetric analysis (TGA), X-ray diffraction (XRD) coupled with Rietveld quantitative analysis (RQA), and X-ray absorption near-edge structure (XANES) studies. In addition, the microscopic properties of the catalyst were revealed by Transmission electron microscopy (TEM) as well as with Scanning electron microscopy (SEM) coupled with the Energy dispersive X-ray spectroscopy (EDX). Since the details of this catalyst's properties are available in earlier work [7], the results are summarized here for the benefit of the reader.

\subsubsection{BET Surface Area Analysis}

The fresh Co-only (Co/C) catalyst was determined to be both nanometric and non-porous in nature, but with a high BET specific surface area of about $56 \mathrm{~m}^{2} \cdot \mathrm{g}^{-1}$, pore diameter of about $28 \mathrm{~nm}$ and total pore volume of $0.39 \mathrm{~cm}^{3} \cdot \mathrm{g}^{-1}$ as given in Table 2 .

Table 2. Catalyst porosity analysis results by the BET method.

\begin{tabular}{ccc}
\hline Property & Auxiliary Plasma Reactor ${ }^{*}$ & Main Plasma Reactor * $^{*}$ \\
\hline BET surface area $\left(\mathrm{m}^{2} \cdot \mathrm{g}^{-1}\right)$ & 55.5 & 54.4 \\
Average pore diameter $(\mathrm{nm})^{\$}$ & 27.4 & 28.3 \\
Total pore volume $\left(\mathrm{cm}^{3} \cdot \mathrm{g}^{-1}\right)$ & 0.38 & 0.39 \\
\hline
\end{tabular}

$\mathrm{BET}=$ Brunauer-Emmett-Teller specific surface area analysis. ${ }^{*}$ The plasma reactor design in catalyst synthesis comprises the auxiliary and main reactors, see Section 4.3.1. \$ Single point adsorption total pore volume of pores less than $120 \mathrm{~nm}$ in diameter at $P / P \mathrm{o}=0.98$. " Average pore diameter $(4 \mathrm{~V} / \mathrm{A}$ by BET).

Figure 1a depicts the non-porous nature of the material from its adsorption-desorption isotherms and Figure $1 \mathrm{~b}$ provides the basis of interpretation. A steep isotherm in the low pressure region below $P / P \mathrm{O}=0.30$ means that the sample is micro-porous (type I isotherm), but since our plot was almost flat in that portion (type II isotherm), it implied that the catalyst was not microporous. In addition, the lack of hysteresis in the desorption arm of the isotherm indicated that the sample was non-porous. Figure 1c shows the BET transform plot with a perfect linear fit on the adsorption isotherm, indicating the high reliability of the method. Normally, solid powder samples with particle diameter in the micrometer range have BET specific surface area of $\sim 1 \mathrm{~m}^{2} \cdot \mathrm{g}^{-1}$. However, when the powder particles are transformed into the nanometer range through plasma, their surface area significantly increases. For example, compact Co spheres of average diameter of $11 \mathrm{~nm}$ have a geometrically calculated 
external specific surface of about $70 \mathrm{~m}^{2} \cdot \mathrm{g}^{-1}$. Therefore, the measured BET surface area of $56 \mathrm{~m}^{2} \cdot \mathrm{g}^{-1}$ is representative of the tested catalyst.

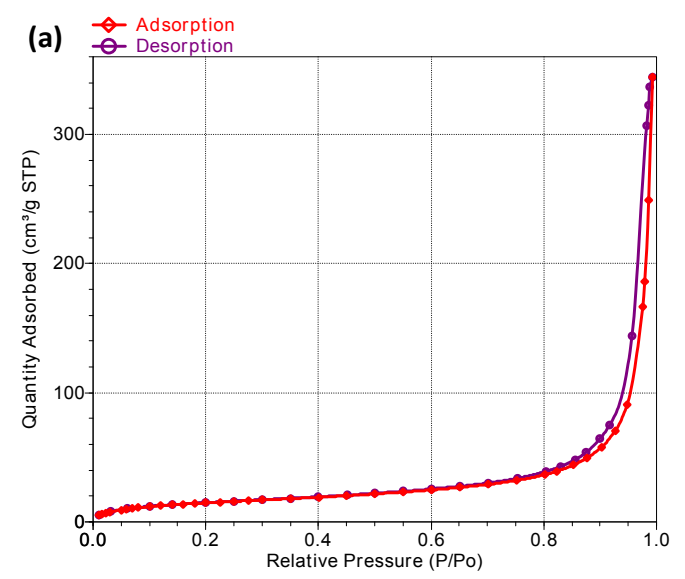

(b)
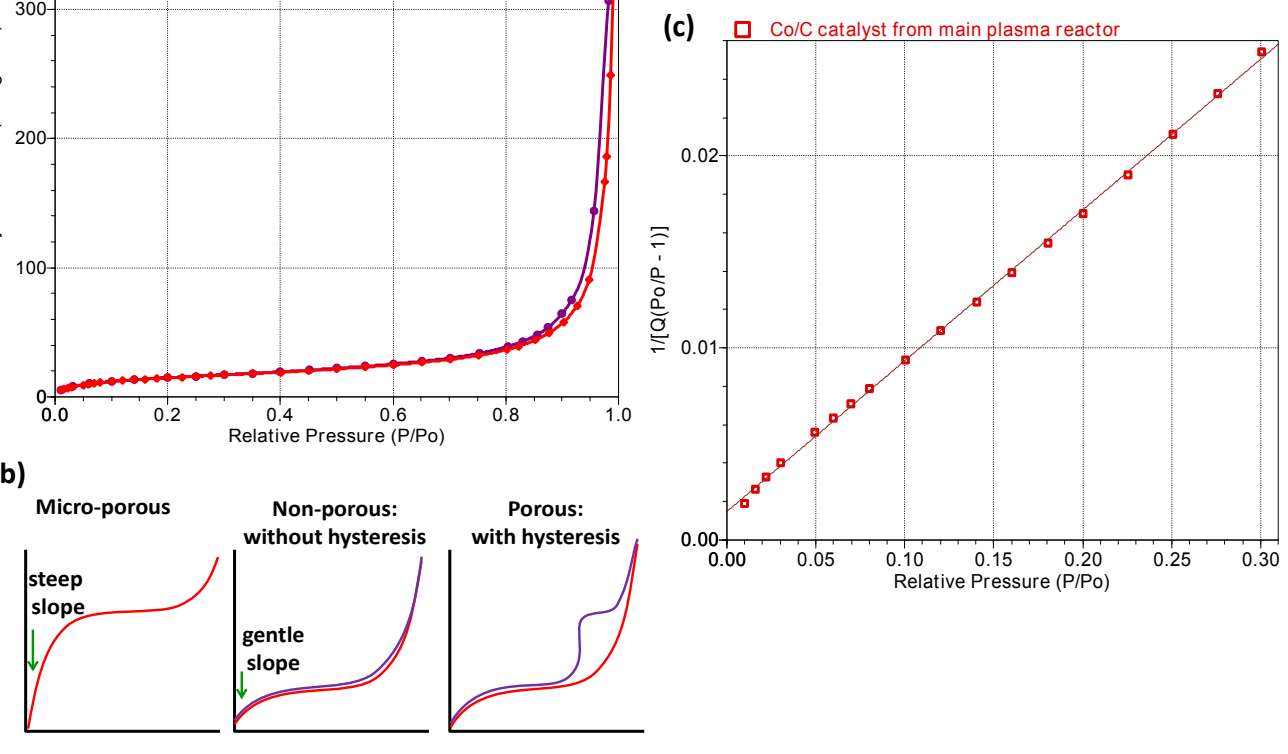

Figure 1. Porosity analysis of the fresh $\mathrm{Co} / \mathrm{C}$ catalyst showing (a) overlaid adsorption-desorption isotherms; (b) cartoons with various impressions of isotherm interpretations; and (c) the BET transform plot.

\subsubsection{Elemental Analysis}

Due to the difficulties experienced in digesting the graphitic C-support for analysis by inductively-coupled plasma mass spectrometry (ICP-MS), TGA by carbon ignition was utilized, which revealed that the $\mathrm{Co}$ atomic-mass loading in the $\mathrm{C}$ matrix was approximately $0.25 \mathrm{~g} / \mathrm{g}(25$-wt. \%) in the freshly synthesized catalysts through plasma.

\subsubsection{Microscopy: Elemental and Particle Size Analysis}

Semi-quantitative SEM analysis coupled with EDX facility showed a Co metal-loading between $20 \%-30 \%$ in the carbon support, as confirmed by TGA (25-wt. \%). Metal nanoparticle-size analysis by TEM imaging manifested a mean size of about $11.0 \mathrm{~nm}$ (counting 750 particles) before and after the reaction [7], as portrayed in Figure 2. This observation alluded to the absence of nanoparticle agglomeration in the spent catalyst sample after a $24-\mathrm{h}$ reduction at $400{ }^{\circ} \mathrm{C}$ followed by another $24 \mathrm{~h}$ of FTS reaction. Figure 3 provides the metal nanoparticle size distribution of 695 particles of the fresh catalyst by TEM analysis, which exhibits a near Gaussian-type distribution, with a standard deviation of 4.4 .

\subsubsection{XRD and RQA Analysis}

XRD analysis revealed the presence of metallic and carbidic species in the catalyst. In order to maximize the catalytic activity measured by $\mathrm{CO}$ conversion during FTS, prior catalyst reduction is paramount because the active species in Co-containing samples are construed to be metallic $\left(\mathrm{Co}^{\circ}\right)$ in nature. Some authors have asserted that the highest CO conversions in FTS are attributed to higher Co reducibility [33], while the oxidation of the Co metal leads to catalyst deactivation [21]. Figure 4 presents the XRD patterns of the fresh Co metal injected into the plasma, which comprised two phases as analysed by RQA: $62 \%$ having face centred cubic (FCC) structure, and 38\% hexagonal closed packing 
(HCP) structure [7]. After plasma synthesis, the Co moieties were perceived to be encapsulated in the carbon matrix and the metal contained only the FCC crystal structure, a phase that prevailed even after the FTS reaction. Since the Co/C catalyst is entirely nanometric, we are convinced that the material probably contains other phases that could be beyond the detection limits of the XRD instrument. However, in the absence of such evidence, we think that the FCC phase is the active form of this catalyst.
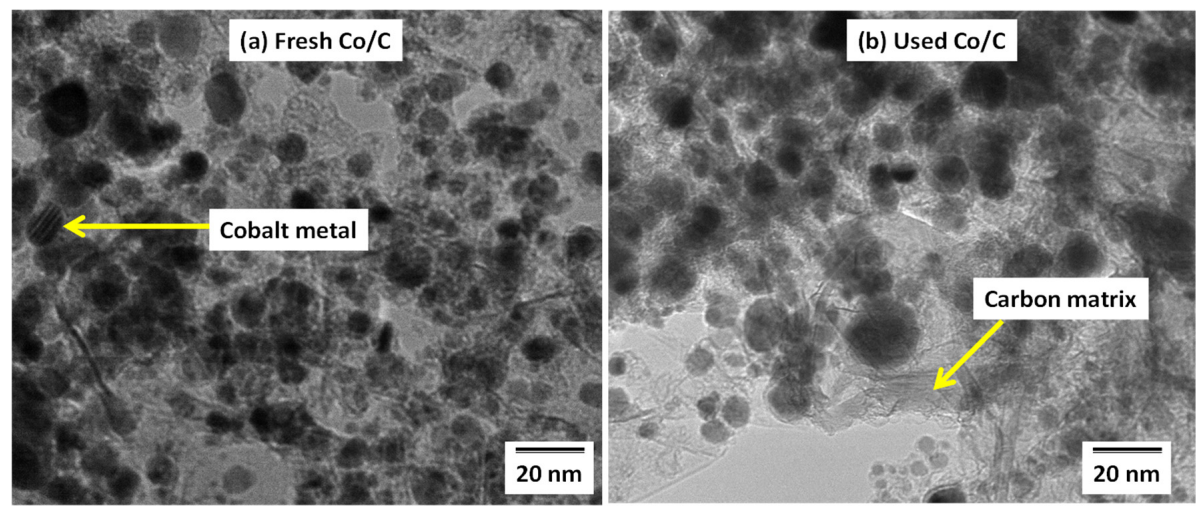

Figure 2. Transmission Electron Microscopic (TEM) images for the fresh and used plasma-synthesized Co/C samples.

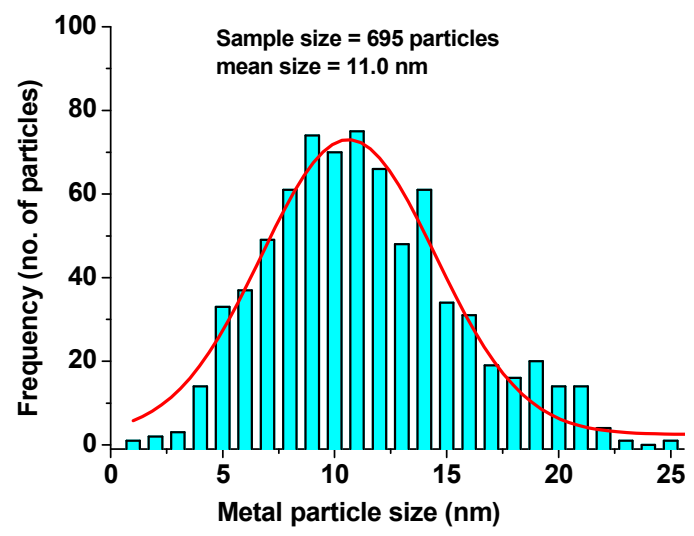

Figure 3. Normal metal particle-size distribution of the fresh Co/C catalyst by TEM analysis.

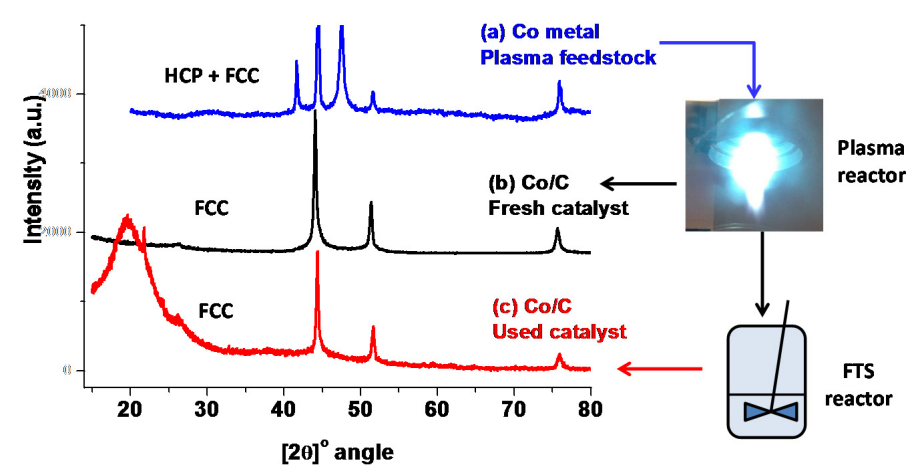

Figure 4. X-ray diffraction (XRD) patterns for the (a) Co metal; (b) freshly plasma-synthesized Co/C catalyst and (c) used sample. 


\subsubsection{XANES Analysis}

Spectral analysis of the fresh and used catalysts by X-ray absorption near-edge structure (XANES) did not indicate any form of oxidation in the samples. However, when compared to the metal-Co standard, a shift of the edge peak in both the fresh and used $\mathrm{Co} / \mathrm{C}$ catalysts was observed, particularly when the derivative plots were examined, as seen in Figure 5. The Co species in the catalysts seemed to have become 'more metallic' in the sense of its electron-donating capability and hence the edge shift to the lower energies of the spectrum [41]. This was perhaps due to the simultaneous presence of metallic and carbidic species in the $\mathrm{Co} / \mathrm{C}$ catalyst samples, as discussed in an earlier article [9]. The carbidic species in the samples were only evidenced by the XRD data analysis through RQA modeling using the High Score Plus software [7]. XANES peak-edge shift to the right implies occurrence of Co oxidation and more often than not leads to catalyst deactivation, whereas peak-edge shift to the left as was observed here, in both the fresh and used samples has a connotation of preventing deactivation, which may prove to be advantageous to the longevity of the catalyst material.
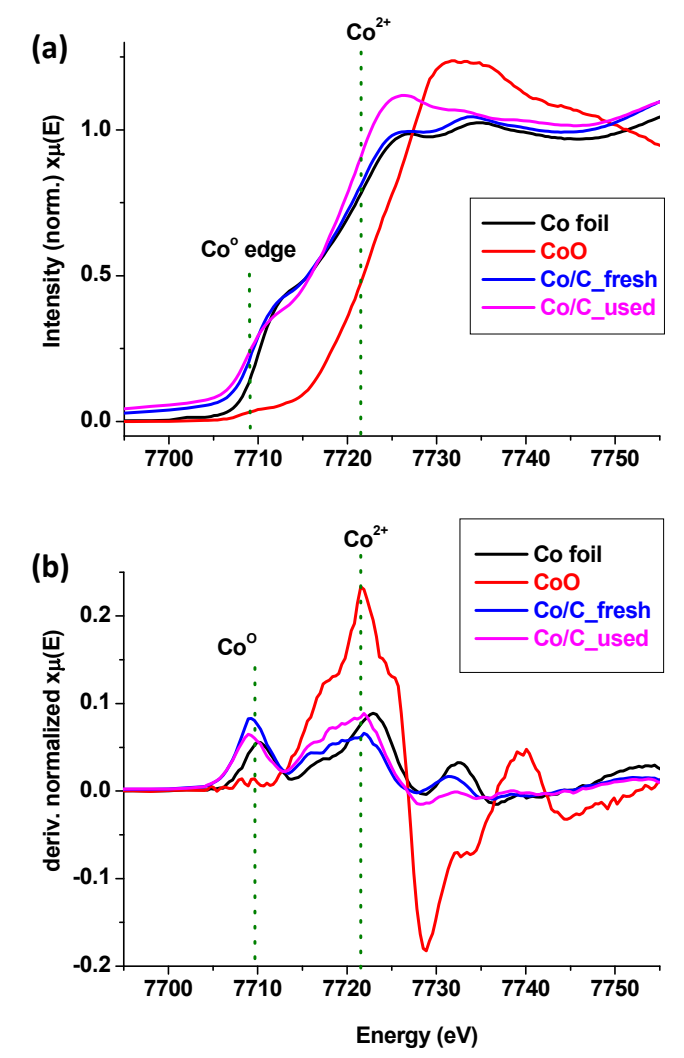

Figure 5. XANES spectra (a) normalized and (b) first derivative of the fresh and used Co/C samples compared with the $\mathrm{Co}^{0}$ and $\mathrm{CoO}$ standards.

\subsection{Catalyst Activity Testing}

Figure 6 represents the catalytic activity at gas hourly space velocity (GHSV) of $3600 \mathrm{~cm}^{3} \cdot \mathrm{g}^{-1} \cdot \mathrm{h}^{-1}$ of catalyst, which presented between $38 \%$ and $43 \%$ CO conversion for the molar feed-gas ratio of $\mathrm{H}_{2}: \mathrm{CO}=2$. This finding was consistent with our earlier work [7]. For the CO-rich feed gas of molar ratio of $\mathrm{H}_{2}: \mathrm{CO}=1.5$ and 1.0, catalytic activity dropped to $20 \%$ and $10 \% \mathrm{CO}$ conversion respectively.

\subsection{Catalyst Selectivity}

Since the modification on the FTS reactor system offered capacity to simultaneously perform both gas-phase and liquid-phase analysis, combining the results provided a full portrait of the FTS product-spectrum in real time. Figure 7 demonstrates the progressive polymerization occurring in the 
liquid-phase with TOS. The slurry was sampled 5 times (after $2 \mathrm{~h}, 5 \mathrm{~h}, 8 \mathrm{~h}, 17 \mathrm{~h}$ and $19 \mathrm{~h}$ of FTS reaction). This procedure was repeated for another experiment, which produced similar results displaying the incremental change perceived in the liquid-phase of the FTS product distribution.

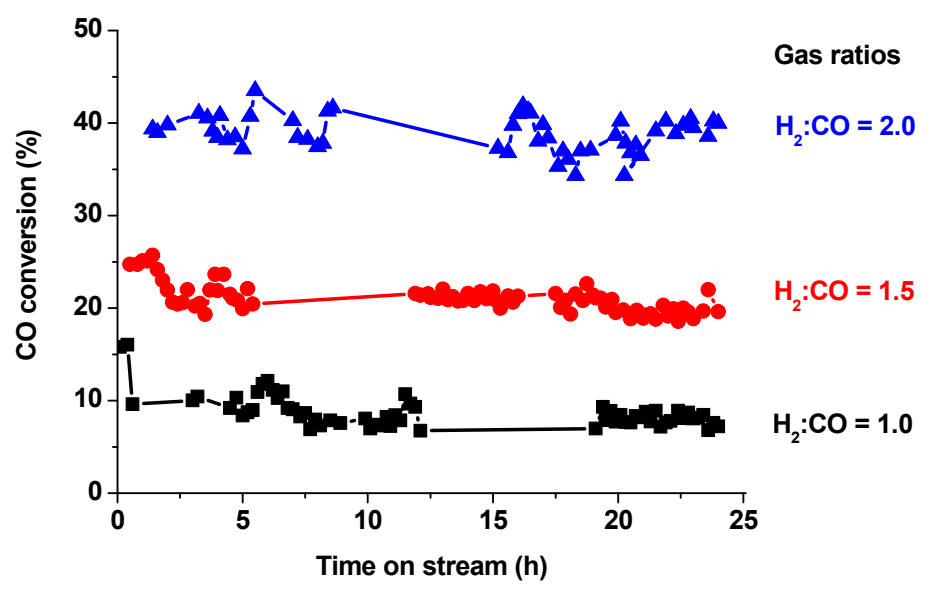

Figure 6. Plots showing the positive influence of $\mathrm{H}_{2}$ on FTS reaction with TOS using the $\mathrm{Co} / \mathrm{C}$ catalyst tested at $220^{\circ} \mathrm{C}, 2 \mathrm{MPa}$ and GHSV of $3600 \mathrm{~cm}^{3} \cdot \mathrm{g}^{-1} \cdot \mathrm{h}^{-1}$.

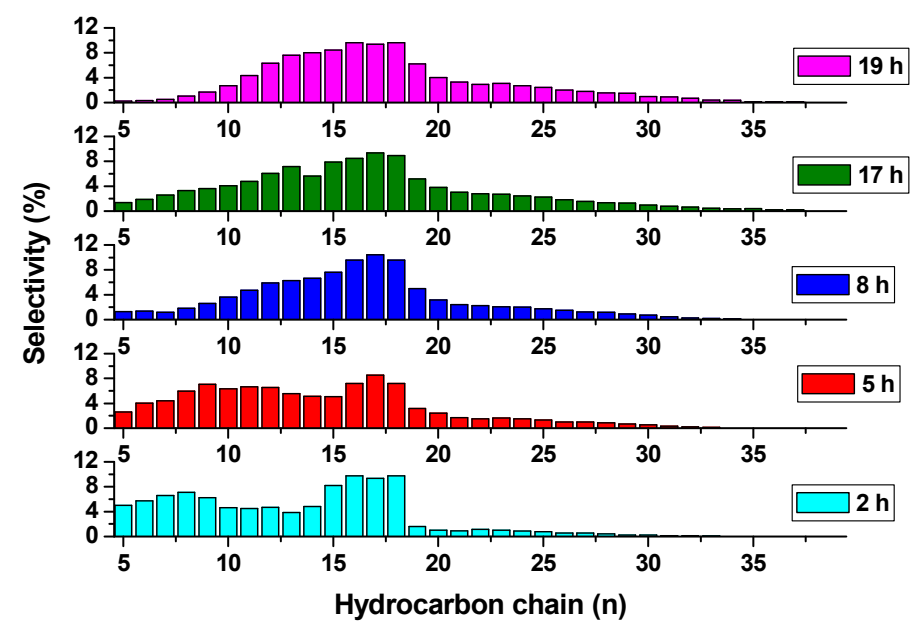

Figure 7. Catalyst selectivity from liquid-sample analysis at various TOS for reaction performed at $220{ }^{\circ} \mathrm{C}, 2 \mathrm{MPa}$ and GHSV of $3600 \mathrm{~cm}^{3} \cdot \mathrm{g}^{-1} \cdot \mathrm{h}^{-1}$ with $\mathrm{H}_{2}: \mathrm{CO}$ ratio $=2$.

The emerging trend indicated that with passage of time from $2 \mathrm{~h}$ to $19 \mathrm{~h}$, there was a substantial transformation from the shorter hydrocarbon chains to the higher molecular-weight fractions. For example, about $5 \%$ of $C_{5}$ existed at $2 \mathrm{~h}$, diminishing to almost zero at $19 \mathrm{~h}$. At the same time, the waxes that were present in very minute quantities at $2 \mathrm{~h}$ had increased considerably at $19 \mathrm{~h}$. From the gas-phase analysis, a high production of $\mathrm{CH}_{4}$ was recorded initially, making up to $11 \%$, but dropped to approximately $8 \%$ after $6 \mathrm{~h}$, and below $4 \%$ at $24 \mathrm{~h}$. The combined $\mathrm{C}_{2}$ 's $\left(\mathrm{C}_{2} \mathrm{H}_{6}\right.$ and $\left.\mathrm{C}_{2} \mathrm{H}_{4}\right)$ gave a total of about $0.6 \%$, while the composition of $\mathrm{CO}_{2}$ was only $0.5 \%$ in the effluent stream. No $\mathrm{C}_{3}$ or $\mathrm{C}_{4}$ compounds were detectable. Figure 8 provides the full spectrum of the FTS product distribution at various $\mathrm{H}_{2}: \mathrm{CO}$ ratios of 2.0, 1.5 and 1.0 that indicated a shift to the lower molecular weights as the $\mathrm{H}_{2}$ :CO ratio increased from 1 to 2 . 


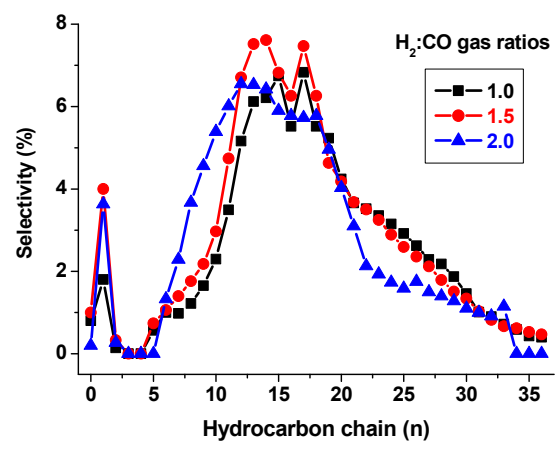

Figure 8. Effect of gas composition on the product spectrum of Fischer-Tropsch synthesis (FTS) after $24 \mathrm{~h}$ on stream at $220^{\circ} \mathrm{C}, 2 \mathrm{MPa}$ and gas hourly space velocity (GHSV) of $3600 \mathrm{~cm}^{3} \cdot \mathrm{g}^{-1} \cdot \mathrm{h}^{-1}$.

\subsection{Determination of $\alpha$-Values}

Since our GC column was incapable of distinguishing the hydrocarbon compounds entirely by their various functional groups, in combining together all molecules with equal number of carbon atoms (alkanes, alkenes oxygenates, etc.), it was assumed that the formation of FTS products conformed to the conventional (ASF) polymerization kinetics, quantitatively described as requiring the presence of only one type of chain-growth site. Given that the catalyst was both nanometric and non-porous, heat and mass transport effects were essentially eliminated, so we suppose since earlier optimization tests indicated the same [42]. As presented in Figure 9, results of $\log \left(\mathrm{M}_{n} / n\right)$ versus $\mathrm{n}$ demonstrated the typical deviation from the normal ASF distribution [43], due to the formation of significant amounts of $\mathrm{CH}_{4}$ followed immediately by almost a non-existent $\left(\mathrm{C}_{2}-\mathrm{C}_{5}\right)$ portion. This created a dip in the plot as seen in Figure 9a: with very little of $\mathrm{C}_{2} \mathrm{H}_{6}$ and $\mathrm{C}_{2} \mathrm{H}_{4}$ observed (amounting to less than $1 \%$, when combined).

From $C_{4}$ there was a sharp rise towards $C_{6}$ that gently increased to $C_{10}$. Beyond $C_{10}$ one may observe two definite gradients: a gentle one between $C_{10}-C_{16}$ and a steeper one above $C_{16}$ that is detectable from Figure 9b. Solving for $\log (\alpha)$ in Equation (4) revealed that the $\alpha$-value for the $\mathrm{Co} / \mathrm{C}$ catalyst was approximately 0.87 , which was attained very quickly at low GHSV of $1800 \mathrm{~cm}^{3} \cdot \mathrm{h}^{-1} \cdot \mathrm{g}^{-1}$ of catalyst using $\mathrm{H}_{2}: \mathrm{CO}=2$. Analyses for samples tested at GHSV of $3600 \mathrm{~cm}^{3} \cdot \mathrm{h}^{-1} \cdot \mathrm{g}^{-1}$ using various $\mathrm{H}_{2}$ :CO ratios of 2.0, 1.5 and 1.0 are provided in Figure 10 showing that the CO-rich gas streams (of $\mathrm{H}_{2}: \mathrm{CO}$ ratios of 1.5 and 1.0) displayed the higher $\alpha$-value of 0.93 , and attained the maximum value within $\sim 6 \mathrm{~h}$, while the $\mathrm{H}_{2}$-rich gas stream $\left(\mathrm{H}_{2}: \mathrm{CO}=2\right)$ showed a lower $\alpha$-value of 0.85 , which was only attained after over $15 \mathrm{~h}$ on stream.
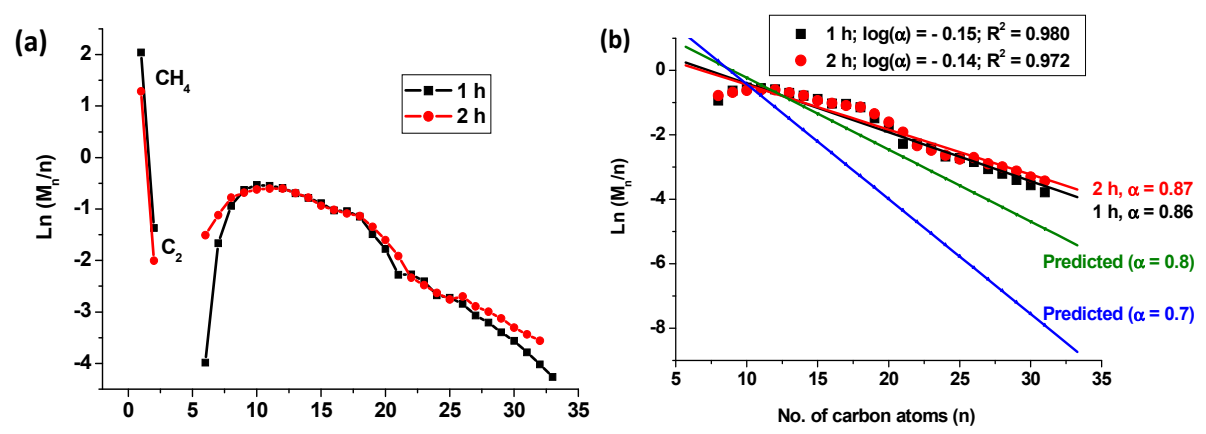

Figure 9. Plots of $\log \left(\mathrm{M}_{n} / n\right)$ versus $\mathrm{n}$ comparing predicted (literature data value) and the measured $\alpha$-values of Co/C catalyst after $1-2 \mathrm{~h}$ on stream, tested at $220^{\circ} \mathrm{C}, 2 \mathrm{MPa}$ and GHSV $=1800 \mathrm{~cm}^{3} \cdot \mathrm{h}^{-1} \cdot \mathrm{g}^{-1}$.

Table 3 summarizes the aggregate product fractions as obtained at the end of the reaction (TOS $=24 \mathrm{~h}$ ) using the various gas feeds, which when the liquid-phase products were transmuted into the graphical format as shown in Figure 11 indicated that application of low $\mathrm{H}_{2}$ :CO ratios suppresses 
$\mathrm{H}_{2} \mathrm{O}$ production, but enhances wax formation. High $\mathrm{H}_{2}$ :CO ratio of 2 only influences additional formation of gasoline, because diesel production remains more or less constant at all $\mathrm{H}_{2}$ : $\mathrm{CO}$ ratios. Prolonged reaction times were observed to shift the product spectrum from the gasoline fraction to the wax fraction, with little net impact on the quantity of diesel formed. Nonetheless, overall the catalyst was perceived to be more selective towards the production of the diesel-fraction $(\sim 45 \%)$, which was in fact, our target product. A convergence of gradients towards the highest possible $\alpha$-value $(\sim 0.85)$ was observed to form a common product spectrum at higher residence times (above $15 \mathrm{~h}$ ).

Table 3. Product fractions with various feed gas compositions at $24 \mathrm{~h}$ of FTS reaction tested at $220^{\circ} \mathrm{C}$, $2 \mathrm{MPa}$ and GHSV of $3600 \mathrm{~cm}^{3} \cdot \mathrm{g}^{-1} \cdot \mathrm{h}^{-1}$.

\begin{tabular}{ccccccccc}
\hline \multirow{2}{*}{$\begin{array}{c}\text { Feed Gas } \\
\left(\mathbf{H}_{\mathbf{2}} \text { :CO Ratio) }\right.\end{array}$} & $\mathbf{C O}_{\mathbf{2}}$ & $\mathbf{C H}_{\mathbf{4}}$ & $\mathbf{C}_{\mathbf{2}}$ & $\mathbf{C}_{\mathbf{5}}-\mathbf{C}_{\mathbf{1 2}}$ & $\mathbf{C}_{\mathbf{1 3}}-\mathbf{C}_{\mathbf{2 0}}$ & $\mathbf{C}_{\mathbf{2 1 +}}$ & $\mathbf{H}_{\mathbf{2}} \mathbf{O}\left(\mathbf{c m}^{\mathbf{3}}\right)$ & $\alpha$-Value \\
\hline 1.0 & 0.8 & 1.8 & 0.1 & 16.4 & 46.4 & 31.1 & 21 & 0.93 \\
1.5 & 1.0 & 4.0 & 0.3 & 21.6 & 45.6 & 28.5 & 33 & 0.93 \\
2.0 & 0.2 & 3.6 & 0.3 & 29.8 & 45.1 & 20.6 & 52 & 0.85 \\
\hline
\end{tabular}
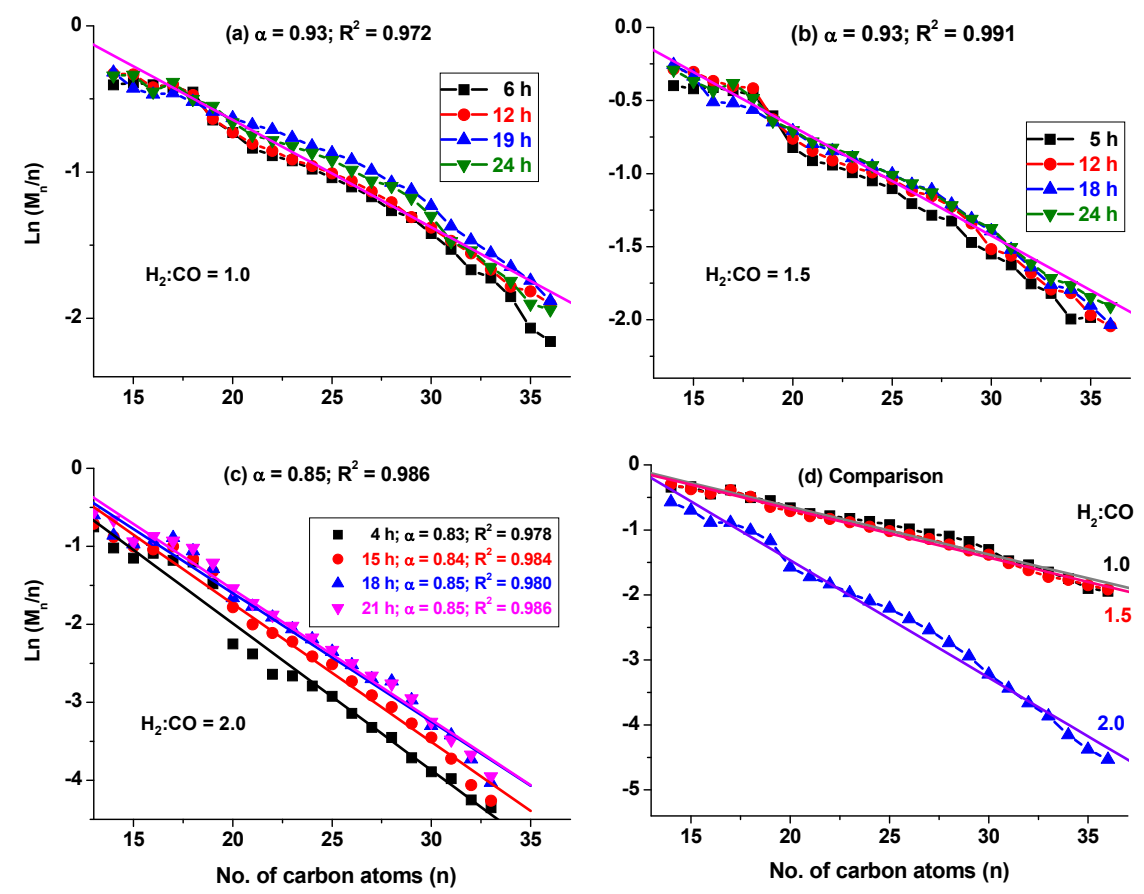

Figure 10. Plots displaying fast convergence and higher $\alpha$-values for $\mathrm{CO}$-rich feed gases with $\mathrm{H}_{2}: \mathrm{CO}$ ratio of $(\mathbf{a})=1.0,(\mathbf{b}) 1.5,(\mathbf{c}) 2.0$, and (d) their comparison after $24 \mathrm{~h}$ on stream at $220^{\circ} \mathrm{C}, 2 \mathrm{MPa}$ and GHSV of $3600 \mathrm{~cm}^{3} \cdot \mathrm{g}^{-1} \cdot \mathrm{h}^{-1}$.

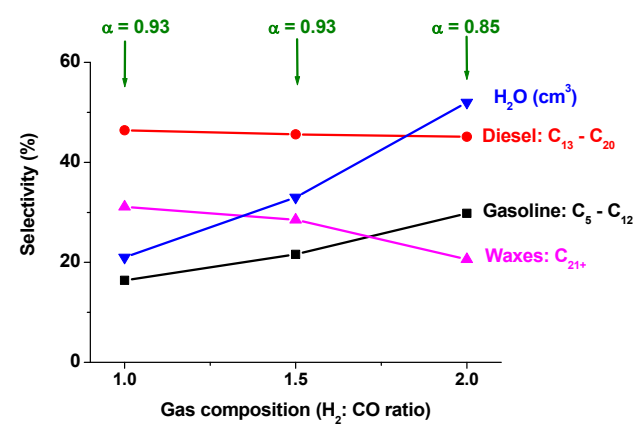

Figure 11. Impact of gas composition on FTS product fractions after $24 \mathrm{~h}$ on stream with catalyst samples tested at $220^{\circ} \mathrm{C}, 2 \mathrm{MPa}$ and GHSV of $3600 \mathrm{~cm}^{3} \cdot \mathrm{g}^{-1} \cdot \mathrm{h}^{-1}$. 


\section{Discussion}

\subsection{Evaluation of Research Objectives}

The application of nanometric catalysts in this work was targeted for two main reasons: that the FTS product selectivity is strongly influenced by the size of Co nanoparticles [30], and that it is desirable to operate the reactor away from diffusion-limiting regimes. Due to the nature of the reaction, the large polymeric molecules especially the waxes generated in due course may easily clog catalyst pores and lead to catalyst deactivation. Therefore, the application of both nanometric and non-porous catalysts with high BET specific surface area of $\sim 56 \mathrm{~m}^{2} \cdot \mathrm{g}^{-1}$ of catalyst have been posited to be ideal for LT-FTS [7]. From our initial research objectives, it is hereby concluded that the plans were successfully executed and our product targets achieved since we were able to:

(i) Use a specially designed liquid sampling column to provide empirical evidence for the gradual development of the longer-chain hydrocarbons from real-time liquid-phase analysis, illustrating hydrocarbon-chain propagation with TOS;

(ii) Determine the true $\alpha$-value of the plasma-synthesized Co/C catalyst as being above 0.85 , which could only be ascertained after over $15 \mathrm{~h}$ on stream, since any $\alpha$-values determined below this time period may be misleading;

(iii) Establish that the application of CO-rich syngas, which may in future be derived from biomass, is a viable alternative that can replace the current use of $\mathrm{H}_{2}$-rich syngas in generating high molecular FTS products.

Microscopy through SEM coupled with EDX indicated uniform distribution of metal moieties in the carbon matrix, while TEM analysis showed highly dispersed Co nanoparticles of mean particle size of $\sim 11 \mathrm{~nm}$. Both XANES and XRD hinted to the fact that the used catalyst samples did not undergo metal oxidation, a characteristic that may prove to be beneficial to the longevity of the catalyst. In addition, XRD analysis revealed that the FCC crystal structure of the Co catalyst was the predominant and possibly the active phase in the FTS reaction [7], although some scholars have provided evidence for potentially greater intrinsic activity displayed by the HCP phase of the Co catalyst [44]. The catalytic activity for CO conversion was shown to greatly increase for catalysts with a majority of HCP stacking compared to those containing mostly the FCC phase particles [45]. In our plasma-synthesized Co/C sample, the existing HCP phase in the initial Co metal was completely transformed into the FCC phase and the catalyst was still very active. This contrasts with literature data where catalysts that contain mainly the HCP crystal structure show more active catalysis for $\mathrm{CO}$ hydrogenation than the FCC crystal structure of the Co metal obtained from $\mathrm{Co}_{3} \mathrm{O}_{4}$ reduction [4]. Besides, the HCP structure favours a different reaction mechanism, which involves direct $\mathrm{CO}$ dissociation, while the FCC structure kinetically favours the H-assisted CO dissociation mechanism on the Co metal [44]. We are of the opinion that there is full dependence on the presence of $\mathrm{H}_{2}$ to dissociate $\mathrm{CO}$ on the FCC phase, because the metal nanoparticle-size range in our samples can only produce the stable FCC structure, while the HCP would automatically undergo a phase transformation. A summary of the catalyst's properties are provided in Table 4.

\subsection{Application of Biomass and Bio-Syngas as Game Changer in Fuel Industry}

This study intended to investigate the possible outcomes of exposing our recently formulated plasma-synthesized Co/C catalyst [9], to a CO-rich FTS feedstock because the composition of syngas feedstock was observed to impact on the FTS product distribution [46]. In this work, application of CO-rich gas feed simulating bio-syngas has established the practicality of producing higher molecular-weight hydrocarbons in FTS, although with lower CO conversions when compared to the $\mathrm{H}_{2}$-rich feeds. The high $\alpha$-value of 0.93 obtained (at $220{ }^{\circ} \mathrm{C}$ and $2 \mathrm{MPa}$ ) for $\mathrm{CO}$-rich inlet stream would be a beneficial characteristic to the plasma-synthesized $\mathrm{Co} / \mathrm{C}$ catalyst, particularly when considering the use of biomass-derived syngas feeds. 
Table 4. Summary details of the properties of the plasma synthesized Co/C catalyst.

\begin{tabular}{|c|c|c|c|}
\hline Measurement & Method & Catalyst Property & Values \\
\hline Metal loading in carbon support & Carbon ignition, SEM & Co atomic-mass (g/g) & 0.25 \\
\hline Catalyst composition & XRD, XANES & $\begin{array}{c}\text { Phases present } \\
\text { Dominant structure }\end{array}$ & $\begin{array}{c}\mathrm{Co}^{0}, \mathrm{Co}_{3} \mathrm{C} \\
\text { FCC }\end{array}$ \\
\hline Porosity & $\mathrm{N}_{2}$ physisorption by BET & $\begin{array}{l}\text { BET surface area }\left(\mathrm{m}^{2} \cdot \mathrm{g}^{-1}\right) \\
\text { Mean pore diameter }(\mathrm{nm}) \\
\text { Total pore volume }\left(\mathrm{cm}^{3} \cdot \mathrm{g}^{-1}\right)\end{array}$ & $\begin{array}{c}56 \\
28 \\
0.39\end{array}$ \\
\hline Metal nanoparticles & Microscopy, TEM & Mean particle size $(\mathrm{nm})$ & 11 \\
\hline Alpha-values & ASF product distribution & $\begin{array}{l}\mathrm{H}_{2}: \mathrm{CO} \text { ratio } 1.0 \\
\mathrm{H}_{2}: \mathrm{CO} \text { ratio } 1.5 \\
\mathrm{H}_{2}: \mathrm{CO} \text { ratio } 2.0\end{array}$ & $\begin{array}{l}0.93 \\
0.93 \\
0.85\end{array}$ \\
\hline Catalyst activity & GC analysis & $\begin{array}{c}\mathrm{CO} \text { conversion }\left(220^{\circ} \mathrm{C}, 2 \mathrm{MPa}\right) \\
\mathrm{H}_{2}: \mathrm{CO} \text { ratio } 1.0 \\
\mathrm{H}_{2}: \mathrm{CO} \text { ratio } 1.5 \\
\mathrm{H}_{2}: \text { CO ratio } 2.0\end{array}$ & $\begin{array}{l}10 \% \\
20 \% \\
40 \%\end{array}$ \\
\hline Selectivity & $\begin{array}{c}\text { Liquid-GC analysis FTS at } \\
220^{\circ} \mathrm{C}, 2 \mathrm{MPa}, \mathrm{H}_{2}: \mathrm{CO}=2.0\end{array}$ & $\begin{array}{c}\text { Sample product distribution: } \mathrm{CO}_{2} \\
\mathrm{CH}_{4} \\
\mathrm{C}_{2}-\mathrm{C}_{4} \\
\mathrm{C}_{5}-\mathrm{C}_{12} \text { (Gasoline) } \\
\mathrm{C}_{13}-\mathrm{C}_{20} \text { (Diesel) } \\
\mathrm{C}_{21+} \text { (Wax) }\end{array}$ & $\begin{array}{c}0.2 \\
3.6 \\
0.3 \\
29.8 \\
45.1 \\
20.6\end{array}$ \\
\hline
\end{tabular}

Since low CO conversions could be expected in the FTS using CO-rich feed stocks, a slight increase in temperature above $220^{\circ} \mathrm{C}$ may enhance catalytic activity and enrich the diesel fraction. Alternatively, the waxes so produced can be converted to diesel fuel by way of thermal or hydrocracking of the waxes so produced. In industry, Co catalysts are designed for maximum selectivity in wax production that in turn acts as a feedstock for hydrocracking, and it is projected that an $80 \%$ selectivity towards diesel fuel can be achieved by blending both the FTS and hydrocracking processes [47]. One of the advantages observed from these results is the rapid chain growth experienced by use of the plasma-derived catalyst, particularly with the application of low $\mathrm{H}_{2}: \mathrm{CO}$ ratios. In addition, since the hydrocarbon-chain growth begins at $\mathrm{C}_{5}$, very limited quantities of $\mathrm{CO}_{2}, \mathrm{C} 2^{\prime}$ s (ethane and ethene), $\mathrm{C}^{\prime}$ 's and $\mathrm{C} 4$ 's were detected, and in fact the $\mathrm{CH}_{4}$ production diminishes with TOS.

\subsection{Catalyst Selectivity and $\alpha$-Values}

In this investigation, there was the typical deviation from the ASF distribution observed at the lower carbon values of $(n \leq 10)$ due to reaction thermodynamics favouring $\mathrm{CH}_{4}$ formation in appreciable quantities (up to $12 \%$ ). However, the conspicuous absence of the $\mathrm{C}_{2}-\mathrm{C}_{4}$ portion cannot be explained from their thermodynamics point of view. For example, in the Fe-catalyzed LT-FTS, a two- $\alpha$-model has been advanced to describe product selectivity, which is correlated to the catalyst's surface properties. The non-polar Fe-carbide surface seems to be responsible for the production of paraffins and olefins, while the polar Fe-oxide surface could be responsible for the production of light hydrocarbons, olefins and oxygenates [48]. The deviation from the ASF distribution has been noted particularly for its poor suitability for nanometric catalytic systems, and this could be an indicator of critical variations in the dominant growth mechanisms of FTS catalyzed by nanoparticles [49]. Since the predicted $\alpha$-values for the Co catalyst by the ASF model is in the range of $0.70-0.80$, our $\mathrm{Co} / \mathrm{C}$ catalyst depending on reaction conditions was found to be greater, in the range of $0.78-0.87$ (for $\mathrm{H}_{2}: \mathrm{CO}=2$ ), and 0.93 (for $\mathrm{H}_{2}: \mathrm{CO} \leq 1.5$ ). The higher $\alpha$-values were validated by the substantial conspicuous solid wax, visible to the naked eye [7]. This creates the impression that liquid GC analysis may only be partially effective since the wax may not dissolve fully in the solvent during analysis.

When heavier components of the product stream are unable to dissolve or accumulate in the solvent, it lowers its amount in the sample drawn for analysis $\left(\alpha=\mathrm{M}_{n+1} / \mathrm{M}_{n}\right)$. A noted classic example is the slow accumulation of the heavier products in the solvent that can lead to negative deviation from the $\alpha$-values predicted by ASF [50]. However, in our case, the values were higher than those predicted. A possible explanation is that with the use of nanometric and non-porous materials, no diffusion limitations existed and hence the apparent instantaneously availability of the FTS products in the 
solvent for analysis. Besides, it is also thought that since the heavier hydrocarbons take longer to move away from the catalyst surface, by virtue of their size, they have greater re-adsorption probability after formation [51]. Other authors indeed agree with the supposition that the olefin-chain length influences re-adsorption rate because the strength of molecular physisorption on catalyst surface increases its solubility in FTS wax with growing chain length and this olefin re-adsorption model was used to accurately predict product selectivity over the entire range of their experimental conditions [14]. It is for this reason that we think our nanometric catalysts are efficient in the process of hydrocarbon chain-growth propagation because no diffusion limitations seem to exist.

\section{Experimental Section}

\subsection{Catalyst Synthesis: Reagents}

The raw materials used for catalyst synthesis and testing were: cobalt metal powder with particle size range of 1-10 $\mu \mathrm{m}$ and cobalt (II) oxide (Aldrich, Milwaukee, WI, USA); high purity FTS feed stock gases (PRAXAIR, Sherbrooke, QC, Canada) composing $\mathrm{H}_{2}$ (N5.0), $\mathrm{CO}$ (N2.5), and Ar (N5.0); mineral oil (Fisher Scientific, Ottawa, ON, Canada), with catalog name "O122-4, Mineral Oil, Heavy; USP/FCC (Paraffin Oil, Heavy)", and 99\% pure n-hexadecane solvent (Fisher Scientific, Whitby, ON, Canada).

\subsection{Catalyst Characterization}

The Co/C catalyst under review has already been fully characterized: initially by XANES (Canadian Light Source (CLS) Synchrotron, Saskatoon, SK, Canada), and for porosity and BET specific surface area using the Accelerated Surface Area Porosimeter (ASAP) 2020 instrument (Micromeritics, Norcross, GA, USA) [9], and later the quantitative elemental analysis for the Co metal in the C support was performed by the carbon ignition method using a TG-DTA Setsys 2400 instrument (Setarum, Hillsborough, NJ, USA), while phase analysis was conducted on a Philips X'pert PRO X-ray Diffractometer (PANalytical, EA Almelo, The Netherlands), which is fitted with Ni-filters for the $\mathrm{Cu}$ $\mathrm{K} \alpha$ radiation of wavelength alpha1 $=1.5406 \AA$, produced at $40 \mathrm{kV}$ and $50 \mathrm{~mA}$ (PANalytical, EA Almelo, The Netherlands). Curve-fitting modeling to determine the various amounts of each species in the catalyst was done using the PANalytical's High Score Plus software by Rietveld Quantitative Analysis (RQA).

In addition, the microscopic properties of the material were revealed by a Hitachi S-4700 Scanning Electron Microscope (SEM), equipped with an X-Max Oxford EDX spectrometer for elemental analysis (Hitachi, Tokyo, Japan). On the other hand, analysis by Transmission Electron Microscopy (TEM) was conducted on a Hitachi H-7500 Microscope, fitted with tungsten filament operated at an accelerating electron beam of $120 \mathrm{kV}$. A bottom-mounted AMT 4k x 4k CCD Camera System Model X41 captured images in bright field mode. (Hitachi, Tokyo, Japan) [7]. Comprehensive test procedures and analysis conditions are therefore provided in the cited articles.

\subsection{Reactor Designs}

\subsubsection{Plasma Synthesis Reactor}

The reactor set-up and detailed production of the catalyst synthesis method through plasma has been provided in an earlier article [30], where two reactor vessels were used to trap the synthesized materials. The first vessel, which confines the plasma plume is regarded as the main plasma reactor, while the auxiliary reactor lies adjacent to the main plasma reactor and both of them are connected through a junction where the fine-powder catalyst particles are captured on filters during the high vacuum evacuation. 


\subsubsection{Fischer-Tropsch Synthesis Reactor (3- $\phi$-CSTSR)}

The catalyst was tested in a 3-phase continuously-stirred tank slurry reactor vessel with a holding capacity of $0.5 \mathrm{~L}$ (Autoclave Engineers, Erie, PA, USA). In the current work, the original reactor design [7] was modified, in that, a liquid-phase sampling line was introduced into the reactor as shown in Figure 11. The sampling pipe for the slurry originated from the bottom of the vessel, while the gas-phase sampling pipe originated from the top of the reactor. The scheme incorporated a method intended to draw the slurry safely at high temperature and pressure without interrupting the reaction by use of a 15-cm long liquid-sampling column having a 1.5- $\mathrm{cm}$ internal diameter.

\subsection{Liquid Sampling}

Before sampling the slurry, all valves were shut, then valve-1 in Figure 12 was opened to allow the reactor pressure ( $2 \mathrm{MPa})$ to push the piston and hence the liquid, up the sampling column. After shutting valve-1, valve- 2 was opened slowly to release the pressure in the column. While valve- 2 was still open and valve-3 shut, valve-4 was opened carefully to draw out about 1-2 $\mathrm{cm}^{3}$ sample of the slurry into a vial. Having all valves shut, the pressure in the air cylinder was raised slightly above the reactor pressure (e.g., 2.2 MPa). Valve-3 was then opened progressively in order to push the piston back to the bottom of the sampling column thereby pushing the untapped slurry back into the reactor for further reaction. The valve was shut again and by keeping all valves closed, valve- 2 was opened to release the pressure that originated from the air bottle and then the valve was shut again. At the appointed time, the cycle was repeated at various time intervals without interrupting the reaction considerably. The drawn slurry sample was then filtered before injecting about $0.1 \mu \mathrm{m}$ of the liquid sample into the liquid-based GC for analysis.

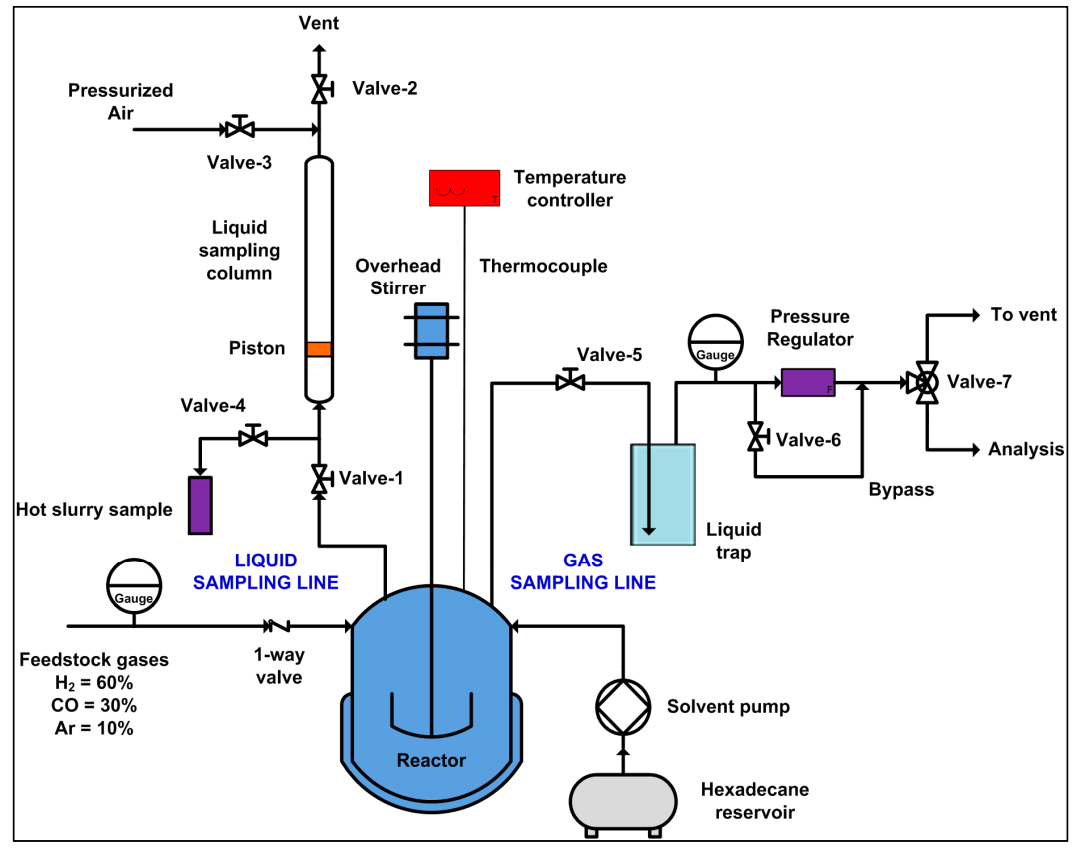

Figure 12. Design of our 3- $\phi$-CSTSR incorporating both liquid and gas sampling lines.

\subsection{Catalyst Testing}

All catalyst samples were pre-treated at $400{ }^{\circ} \mathrm{C}$ for $24 \mathrm{~h}$ in a pure $\mathrm{H}_{2}$ (N5.0) gas stream flowing at RTP, at the rate of $250 \mathrm{SCCM}$, (standard cubic cm per min or $4.17 \times 10^{-6} \mathrm{Nm}^{3} \cdot \mathrm{s}^{-1}$; where $1 \mathrm{SCCM}=1.67 \times 10^{-8} \mathrm{Nm}^{3} \cdot \mathrm{s}^{-1}$ ), while the FTS reaction was carried out in 3- $\phi$-CSTSR operated isothermally at $220^{\circ} \mathrm{C}$ and $2 \mathrm{MPa}$ pressure with a stirring rate of over $2000 \mathrm{rpm}$. The purpose of pre-treatment by reduction is to gasify some of the excess carbon matrix in order to increase exposure 
of the metal nanoparticles to the FTS gas reactants. The initial gas composition was set in the $\mathrm{H}_{2}: \mathrm{CO}$ ratio of 2:1 flowing at $300 \mathrm{SCCM}$ (or $5.01 \times 10^{-6} \mathrm{Nm}^{3} \cdot \mathrm{s}^{-1}$ ), containing $0.6 \mathrm{~L} / \mathrm{L}(60 \mathrm{vol} \%) \mathrm{H}_{2}$ and $0.3 \mathrm{~L} / \mathrm{L}(30 \mathrm{vol} \%) \mathrm{CO}$, balanced in $0.1 \mathrm{~L} / \mathrm{L}$ (10 vol \%) Ar, for mass-balance calculation. At higher temperature (e.g., $260^{\circ} \mathrm{C}$ ), the catalyst became less useful for evaluating the $\alpha$-value due to excessive $\mathrm{CH}_{4}$ production (up to $\sim 46 \%$ ) [52]. Hexadecane $\left(\mathrm{C}_{16}\right)$ solvent was used to make up a reactor volume of $210 \mathrm{~cm}^{3}$, and a mass of $5.0 \mathrm{~g}$ of catalyst utilized to create a gas flow rate with GHSV of $3600 \mathrm{~cm}^{3} \cdot \mathrm{g}^{-1} \cdot \mathrm{h}^{-1}$ of catalyst. The catalyst was doubled to $10.0 \mathrm{~g}$ to deliver a GHSV of $1800 \mathrm{~cm}^{3} \cdot \mathrm{g}^{-1} \cdot \mathrm{h}^{-1}$ of catalyst, while holding all the other reaction parameters constant. In other experiments, the feed gas composition was altered from $\mathrm{H}_{2}$ :CO ratio of 2.0 to 1.5 or to 1.0 .

During the reaction, the gas-phase was sampled and tested for $\mathrm{CO}$ conversion using an at-line GC, while small quantities $\left(1-2 \mathrm{~cm}^{3}\right)$ of the slurry were drawn about five times at various intervals within the 24-h reaction for real-time liquid-phase analysis. The solid-liquid sample was filtered before injecting into the liquid-based GC. From the GC charts, peak areas were computed to determine the selectivity of the product spectrum for both the gas-phase and liquid-phase analyses by a method already described in an earlier article [7]. The $\alpha$-values were obtained by the least-squares linear regression of Equation (3), but in the logarithmic form expressed as Equation (4), where $\log \left(M_{n} / n\right)$ is plotted against $n$ (the hydrocarbon-chain length) [15]. The following typical characteristic ranges of $\alpha$-values for various catalysts: for $\mathrm{Ru}=0.85-0.95$; $\mathrm{Co}=0.70-0.80$; and $\mathrm{Fe}=0.50-0.70$, which are designated in this article as the "predicted" $\alpha$-values [53].

\section{Conclusions}

From the objectives of this work, we developed a safe sampling method of drawing small portions of the hot slurry from a pressured $3-\phi$-CSTSR vessel without significantly interrupting the FTS reaction process. This approach enabled us to provide tangible evidence for the gradual formation and shift of the FTS fractions towards the heavier hydrocarbons with TOS. When tested at $220{ }^{\circ} \mathrm{C}(493 \mathrm{~K}), 2 \mathrm{MPa}$ pressure, and GHSV $=3600 \mathrm{~cm}^{3} \cdot \mathrm{g}^{-1} \cdot \mathrm{h}^{-1}$ of catalyst, results showed that there was lower catalyst activity of $\sim 10 \%$ and $\sim 20 \%$ CO conversion at $\mathrm{H}_{2}$ :CO ratio of 1.0 and 1.5 respectively, with a predominant production of the heavier molecular weight fractions (diesel $=\mathrm{C}_{13}-\mathrm{C}_{20}$ and waxes $=\mathrm{C}_{21+}$ ), giving an $\alpha$-value of 0.93 . A higher catalyst activity ( $\sim 40 \% \mathrm{CO}$ conversion) was witnessed for $\mathrm{H}_{2}: \mathrm{CO}$ ratio of 2.0 with prevalent tendency to produce more light-weight hydrocarbons (gasoline $=\mathrm{C}_{4}-\mathrm{C}_{12}$ ) and this led to relatively lower $\alpha$-value of 0.85 . Although our target fraction in this reaction was to produce diesel fuel as the principal fraction, the $\alpha$-values higher than the predicted figure of $0.8 \mathrm{imply}$ that the catalyst has great propensity to produce $\mathrm{C}_{20+}$ fractions too, particularly under $\mathrm{CO}$-rich gas-feed streams.

Acknowledgments: We thank the Canadian BiofuelNet National Centre of Excellence (NCE) for financial support, Henri Gauvin for technical expertise in the labs; the CCM (Centre de Caractérisation des Matériaux, Université de Sherbrooke) staff for facilitating the characterization: Irène Kelsey Lévesque and Carl St.-Louis for BET surface area analysis, Charles Bertrand for Microscopy (SEM \& TEM), and Stéphane Gutierrez for XRD analysis.

Author Contributions: Catalyst synthesis, testing, characterization, data analysis and manuscript drafting was done by James Aluha, while Nicolas Abatzoglou supervised the entire work and proofread the document. Yongfeng Hu provided access to the Canadian Light Source (CLS) Synchrotron and supervised the XANES analysis.

Conflicts of Interest: The authors declare no conflict of interest.

\section{Abbreviations}

The following abbreviations have been used in this manuscript:

ASF Anderson-Schulz-Flory distribution

ASAP Accelerated surface area porosimeter (Micromeritics ASAP-2020) instrument

BET Brunauer-Emmett-Teller method for specific surface area analysis

EDX Energy dispersive X-ray spectroscopy

FCC Face centred cubic structure

FTS Fischer-Tropsch synthesis 


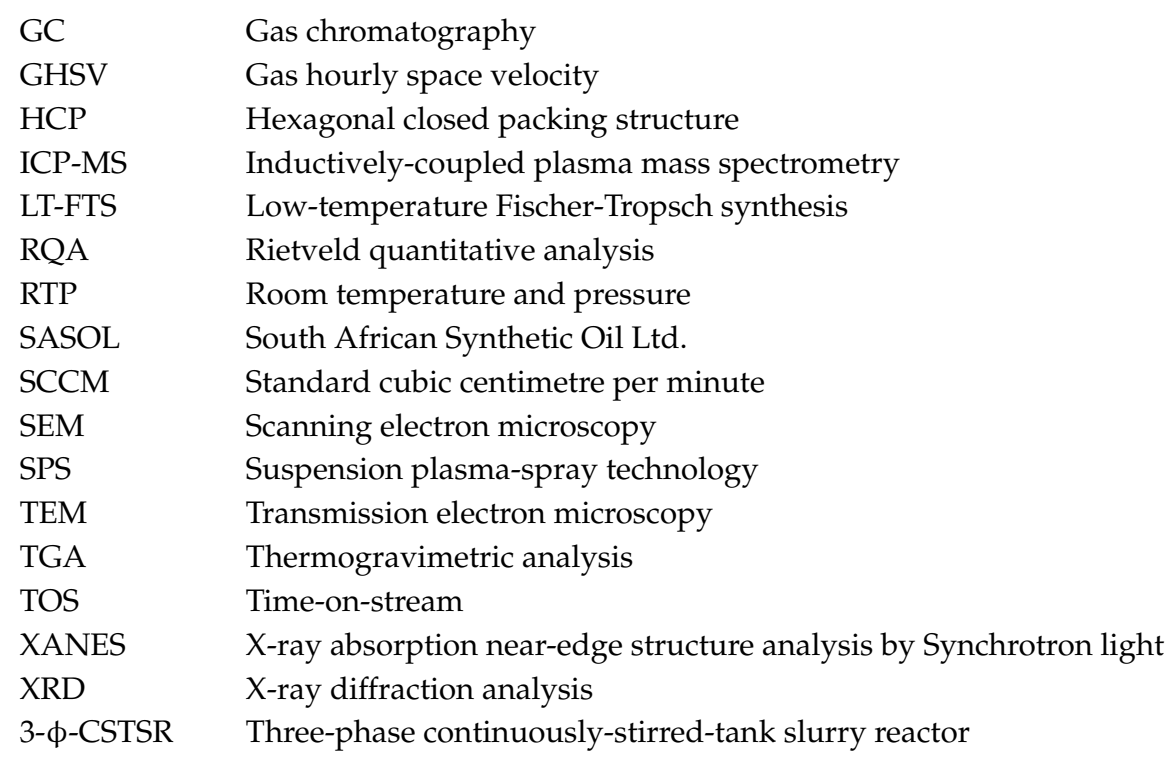

\section{References}

1. Thomas, J.M.; Thomas, W.J. Principles and Practice of Heterogeneous Catalysis; Wiley: Hoboken, NJ, USA, 1997; p. 526.

2. Vosloo, A.C. Fischer-Tropsch: A futuristic view. Fuel Process. Technol. 2001, 71, 149-155. [CrossRef]

3. Ding, M.; Yang, Y.; Wu, B.; Xu, J.; Zhang, C.; Xiang, H.; Li, Y. Study of phase transformation and catalytic performance on precipitated iron-based catalyst for Fischer-Tropsch synthesis. J. Mol. Catal. A Chem. 2009, 303, 65-71. [CrossRef]

4. Kwak, G.; Kim, D.-E.; Kim, Y.T.; Park, H.-G.; Kang, S.C.; Ha, K.-S.; Juna, K.-W.; Lee, Y.-J. Enhanced catalytic activity of cobalt catalysts for Fischer-Tropsch synthesis via carburization and hydrogenation and its application to regeneration. Catal. Sci. Technol. 2016, 6, 4594-4600. [CrossRef]

5. Fu, T.; Jiang, Y.; Lv, J.; Li, Z. Effect of carbon support on Fischer-Tropsch synthesis activity and product distribution over Co-based catalysts. Fuel Process. Technol. 2013, 110, 141-149. [CrossRef]

6. D'Souza, L.; Barnes, S.; Regalbuto, J.R. The simple, effective synthesis of highly dispersed Pd/C and CoPd/C heterogeneous catalysts via charge-enhanced dry impregnation. Catalysts 2016, 6, 1-11. [CrossRef]

7. Aluha, J.; Braidy, N.; Dalai, A.; Abatzoglou, N. Low-temperature Fischer-Tropsch synthesis using plasma-synthesised nanometric Co/C and Fe/C catalysts. Can. J. Chem. Eng. 2016, 94, 1504-1515. [CrossRef]

8. Liu, C.-J.; Zou, J.; Yu, K.; Cheng, D.; Han, Y.; Zhan, J.; Ratanatawanate, C.; Jang, B.W.-L. Plasma application for more environmentally friendly catalyst preparation. Pure Appl. Chem. 2006, 78, 1227-1238. [CrossRef]

9. Aluha, J.; Boahene, P.; Dalai, A.; Hu, Y.; Bere, K.; Braidy, N.; Abatzoglou, N. Synthesis and characterisation of nanometric $\mathrm{Co} / \mathrm{C}$ and $\mathrm{Fe} / \mathrm{C}$ catalysts for Fischer-Tropsch synthesis: A comparative study using a fixed-bed reactor. Ind. Eng. Chem. Res. 2015, 54, 10661-10674. [CrossRef]

10. Tristantini, D.; Lögdberg, S.; Gevert, B.; Borg, Ø.; Holmen, A. The effect of synthesis gas composition on the Fischer-Tropsch synthesis over $\mathrm{Co} / \gamma-\mathrm{Al}_{2} \mathrm{O}_{3}$ and $\mathrm{Co}-\mathrm{Re} / \gamma-\mathrm{Al}_{2} \mathrm{O}_{3}$ catalysts. Fuel Process. Technol. 2007, 88, 643-649. [CrossRef]

11. Chaudhari, S.T.; Bej, S.K.; Bakhshi, N.N.; Dalai, A.K. Steam gasification of biomass-derived char for the production of carbon monoxide-rich synthesis gas. Energy Fuels 2001, 15, 736-742. [CrossRef]

12. Hu, J.; Yu, F.; Lu, Y. Application of Fischer-Tropsch synthesis in biomass to liquid conversion. Catalysts 2012, 2, 303-326. [CrossRef]

13. Aluha, J.; Braidy, N.; Dalai, A.; Abatzoglou, N. Low-temperature fischer-tropsch synthesis with carbon-supported nanometric iron-cobalt catalysts. In Proceedings of the 23rd European Biomass Conference and Exhibition, Vienna, Austria, 1-4 June 2015.

14. van der Laan, G.P.; Beenackers, A.A.C.M. Hydrocarbon selectivity model for the gas-solid Fischer-Tropsch synthesis on precipitated iron catalysts. Ind. Eng. Chem. Res. 1999, 38, 1277-1290. [CrossRef]

15. Bartholomew, C.H.; Farrauto, R.J. Fundamentals of Industrial Catalytic Processes; John Wiley \& Sons, Inc.: Hoboken, NJ, USA, 2006; p. 403. 
16. Fu, T.; Li, Z. Review of recent development in Co-based catalysts supported on carbon materials for Fischer-Tropsch synthesis. Chem. Eng. Sci. 2015, 135, 3-20. [CrossRef]

17. Jacobs, G.; Das, T.K.; Zhang, Y.; Li, J.; Racoillet, G.; Davis, B.H. Fischer-Tropsch synthesis: Support, loading, and promoter effects on the reducibility of cobalt catalysts. Appl. Catal. A 2002, 233, 263-281. [CrossRef]

18. Jacobs, G.; Ma, W.; Gao, P.; Todic, B.; Bhatelia, T.; Bukur, D.B.; Davis, B.H. The application of synchrotron methods in characterizing iron and cobalt Fischer-Tropsch synthesis catalysts. Catal. Today 2013, 214, 100-139. [CrossRef]

19. Ding, M.; Yang, Y.; Wu, B.; Li, Y.; Wang, T.; Ma, L. Study on reduction and carburization behaviors of iron-based Fischer-Tropsch synthesis catalyst. Energy Procedia 2014, 61, 2267-2270. [CrossRef]

20. Khodakov, A.Y.; Chu, W.; Fongarland, P. Advances in the development of novel cobalt Fischer-Tropsch catalysts for synthesis of long-chain hydrocarbons and clean fuels. Chem. Rev. 2007, 107, 1692-1744. [CrossRef] [PubMed]

21. van Berge, P.J.; van de Loosdrecht, J.; Barradas, S.; van der Kraan, A.M. Oxidation of cobalt based Fischer-Tropsch catalysts as a deactivation mechanism. Catal. Today 2000, 58, 321-334. [CrossRef]

22. Van de Loosdrecht, J.; Balzhinimaev, B.; Dalmon, J.A.; Niemantsverdriet, J.W.; Tsybulya, S.V.; Saib, A.M.; van-Berge, P.J.; Visagie, J.L. Cobalt Fischer-Tropsch synthesis: Deactivation by oxidation? Catal. Today 2007, 123, 293-302. [CrossRef]

23. Nabaho, D.; Niemantsverdriet, J.W.H.; Claeys, M.; van Steen, E. Hydrogen spillover in the Fischer-Tropsch synthesis: An analysis of gold as a promoter for cobalt-alumina catalysts. Catal. Today 2016, 275, 27-34. [CrossRef]

24. Den Otter, J.H.; Nijveld, S.R.; de Jong, K.P. Synergistic promotion of Co/SiO 2 Fischer-Tropsch catalysts by niobia and platinum. ACS Catal. 2016, 6, 1616-1623. [CrossRef]

25. Miyazawa, T.; Hanaoka, T.; Shimura, K.; Hirata, S. Ruthenium modification on Mn and Zr-modified Co/SiO 2 catalysts for slurry-phase Fischer-Tropsch synthesis. Catalysts 2015, 5, 26-37. [CrossRef]

26. Fajín, J.L.C.; Cordeiro, M.N.D.S.; Gomes, J.R.B. Fischer-Tropsch synthesis on multicomponent catalysts: What can we learn from computer simulations? Catalysts 2015, 5, 3-17. [CrossRef]

27. Jacobs, G.; Ma, W.; Davis, B.H. Influence of reduction promoters on stability of cobalt $/ \gamma$-alumina Fischer-Tropsch synthesis catalysts. Catalysts 2014, 4, 49-76. [CrossRef]

28. Iqbal, S.; Davies, T.E.; Morgan, D.J.; Karim, K.; Hayward, J.S.; Bartley, J.K.; Taylor, S.H.; Hutchings, G.J. Fischer Tropsch synthesis using cobalt based carbon catalysts. Catal. Today 2016, 275, 35-39. [CrossRef]

29. Rytter, E.; Holmen, A. Deactivation and regeneration of commercial type Fischer-Tropsch Co-catalysts-A mini-review. Catalysts 2015, 5, 478-499. [CrossRef]

30. Aluha, J.; Bere, K.; Abatzoglou, N.; Gitzhofer, F. Synthesis of nano-catalysts by induction suspension plasma technology (SPS) for Fischer-Tropsch reaction. Plasma Chem. Plasma P 2016, 36, 1325-1348. [CrossRef]

31. Borg, Ø.; Eri, S.; Blekkan, E.A.; Storsæter, S.; Wigum, H.; Rytter, E.; Holmen, A. Fischer-Tropsch synthesis over $\gamma$-alumina-supported cobalt catalysts: Effect of support variables. J. Catal. 2007, 248, 89-100. [CrossRef]

32. Abbaslou, R.M.M.; Tavassoli, A.; Soltan, J.; Dalai, A.K. Iron catalysts supported on carbon nanotubes for Fischer-Tropsch synthesis: Effect of catalytic site position. Appl. Catal. A 2009, 367, 47-52. [CrossRef]

33. Trépanier, M.; Tavasoli, A.; Dalai, A.K.; Abatzoglou, N. Fischer-Tropsch synthesis over carbon nanotubes supported cobalt catalysts in a fixed bed reactor: Influence of acid treatment. Fuel Process. Technol. 2009, 90, 367-374. [CrossRef]

34. Fu, T.; Huang, C.; Lv, J.; Li, Z. Fuel production through Fischer-Tropsch synthesis on carbon nanotubes supported co catalyst prepared by plasma. Fuel 2014, 121, 225-231. [CrossRef]

35. Bezemer, G.L.; Bitter, J.H.; Kuipers, H.P.C.E.; Oosterbeek, H.; Holewijn, J.E.; Xu, X.; Kapteijn, F.; van Dillen, A.J.; de Jong, K.P. Cobalt particle size effects in the Fischer-Tropsch reaction studied with carbon nanofiber supported catalysts. J. Am. Chem. Soc. 2006, 128, 3956-3964. [CrossRef] [PubMed]

36. De la Osa, A.R.; Romero, A.; Dorado, F.; Valverde, J.L.; Sánchez, P. Influence of cobalt precursor on efficient production of commercial fuels over FTS Co/SiC catalyst. Catalysts 2016, 6, 98. [CrossRef]

37. Moazami, N.; Mahmoudi, H.; Rahbar, K.; Panahifar, P.; Tsolakis, A.; Wyszynski, M.L. Catalytic performance of cobalt-silica catalyst for Fischer-Tropsch synthesis: Effects of reaction rates on efficiency of liquid synthesis. Chem. Eng. Sci. 2015, 134, 374-384. [CrossRef] 
38. Moazami, N.; Wyszynski, M.L.; Mahmoudi, H.; Tsolakis, A.; Zou, Z.; Panahifar, P.; Rahbar, K. Modelling of a fixed bed reactor for Fischer-Tropsch synthesis of simulated $\mathrm{N}_{2}$-rich syngas over $\mathrm{Co} / \mathrm{SiO}_{2}: H y d r o c a r b o n$ production. Fuel 2015, 154, 140-151. [CrossRef]

39. Hong, J.; Chu, W.; Chernavskii, P.A.; Khodakov, A.Y. Cobalt species and cobalt-support interaction in glow discharge plasma-assisted Fischer-Tropsch catalysts. J. Catal. 2010, 273, 9-17. [CrossRef]

40. Eschemann, T.O.; Bitter, J.H.; de Jong, K.P. Effects of loading and synthesis method of titania-supported cobalt catalysts for Fischer-Tropsch synthesis. Catal. Today 2014, 228, 89-95. [CrossRef]

41. Mohandas, J.C.; Gnanamani, M.K.; Jacobs, G.; Ma, W.; Ji, Y.; Khalid, S.; Davis, B.H. Fischer-Tropsch synthesis: Characterization and reaction testing of cobalt carbide. ACS Catal. 2011, 1, 1581-1588. [CrossRef]

42. Blanchard, J.; Abatzoglou, N. Nano-iron carbide synthesized by plasma as catalyst for Fischer-Tropsch synthesis in slurry reactors: The role of iron loading and K, Cu promoters. Catal. Today 2014, 237, 150-156. [CrossRef]

43. Davis, B.H. The Two-Alpha Value for Iron Fischer-Tropsch Catalysts: Fact or Fiction? ACS Fuel: San Francisco, CA, USA, 2006; Argonne National Laboratory: San Francisco, CA, USA; pp. 173-183.

44. Liu, J.-X.; Su, H.-Y.; Sun, D.-P.; Zhang, B.-Y.; Li, W.-X. Crystallographic dependence of Co activation on cobalt catalysts: HCP versus FCC. J. Am. Chem. Soc. 2013, 135, 16284-16287. [CrossRef] [PubMed]

45. Ducreux, O.; Rebours, B.; Lynch, J.; Roy-Auberger, M.; Bazin, D. Microstructure of supported cobalt Fischer-Tropsch catalysts. Oil Gas Sci. Technol. Rev. IFP 2009, 64, 49-62. [CrossRef]

46. Farias, F.E.M.; Sales, F.G.; Fernandes, F.A.N. Effect of operating conditions and potassium content on Fischer-Tropsch liquid products produced by potassium-promoted iron catalysts. J. Nat. Gas Chem. 2008, 17, 175-178. [CrossRef]

47. Schulz, H. Short history and present trends of Fischer-Tropsch synthesis. Appl. Catal. A 1999, 186, 3-12. [CrossRef]

48. Huyser, J.; van Vuuren, M.J.; Kupi, G. Advances in Fischer-Tropsch synthesis, catalysts, and catalysis. In The Value of a Two Alpha Model in the Elucidation of a Full Product Spetrum for Fe-LTFT; Davis, B.H., Occelli, M.L., Eds.; CRC Press: Boca Raton, FL, USA, 2010; pp. 185-197.

49. Tavakoli, A.; Sohrabi, M.; Kargari, A. Application of Anderson-Schulz-Flory (ASF) equation in the product distribution of slurry phase FT synthesis with nanosized iron catalysts. Chem. Eng. J. 2008, 136, 358-363. [CrossRef]

50. Dictor, R.A.; Bell, A.T. An explanation for deviations of Fischer-Tropsch products from a Schulz-Flory distribution. Ind. Eng. Chem. Proc. Des. Dev. 1983, 22, 678-681. [CrossRef]

51. Iglesia, E.; Reyes, S.C.; Madon, R.J.; Soled, S.L. Selectivity control and catalyst design in the Fischer-Tropsch synthesis: Sites, pellets, and reactors. Adv. Catal. 1993, 39, 221-302.

52. Aluha, J.; Abatzoglou, N. Synthetic fuels from 3- $\phi$ Fischer-Tropsch synthesis using syngas feed and novel nanometric catalysts synthesised by plasma. Biomass Bioenergy 2016, 95, 330-339. [CrossRef]

53. Dry, M.E. Catalytic aspects of industrial Fischer-Tropsch synthesis. J. Mol. Catal. 1982, 17, 133-144. [CrossRef]

(C) 2017 by the authors. Licensee MDPI, Basel, Switzerland. This article is an open access article distributed under the terms and conditions of the Creative Commons Attribution (CC BY) license (http:/ / creativecommons.org/licenses/by/4.0/). 